\title{
Precarização do trabalho de enfermagem e repercussões na saúde dos trabalhadores brasileiros: revisão integrativa
}

\author{
Reflection of nursing labor precarization in brazil for nursing \\ workforce health status: an integrative review
}

\begin{abstract}
Helena Ferraz Gomes ${ }^{1} \bullet$ Francisco Gleidson de Azevedo Gonçalves $^{2} \bullet$ Ariane da Silva Pires $^{3} \bullet$ Rafael Tavares Jomar $^{4} \bullet$ Ellen M. Peres ${ }^{5} \cdot$ Cristiane Helena Gallasch $^{6}$
\end{abstract}

\begin{abstract}
RESUMO
Introdução: $\mathrm{O}$ trabalho em saúde, na atualidade, vem atendendo à lógica do mercado capitalista, na perspectiva de atuação mínima do Estado. Isto interfere diretamente nos modos de produção em saúde, refletindo no processo de trabalho neste setor, no qual se observa uma intensificação da terceirização dos serviços, bem como uma precarização das condições de trabalho. Objetivos: Identificar e caracterizar a produção científica relacionada à precarização do trabalho de enfermagem no Brasil, e avaliar as repercussões da precarização do trabalho na saúde dos trabalhadores de enfermagem. Métodos: Revisão integrativa conduzida entre os meses de dezembro de 2012 e janeiro de 2013 na Biblioteca Virtual em Saúde, a qual inclui, entre outras, as bases de dados LILACS, BDENF e SCIELO. Resultados: A precarização do trabalho de enfermagem relaciona-se à perda de direitos trabalhistas, à baixa remuneração, aos múltiplos vínculos empregatícios, às diversas formas de contratação e jornadas extensas de trabalho e à precarização dos ambientes e de condições de trabalho. Conclusões: A precarização está presente nos diversos ambientes de trabalho da enfermagem com repercussões diretas na saúde dos trabalhadores de enfermagem, causando-lhes adoecimento físico e psíquico.
\end{abstract}

Palavras-chave: Saúde do trabalhador; Enfermagem do trabalho; Condições de trabalho; Relações trabalhistas.

\begin{abstract}
Background: Labor in health services has been serving the logic of the capitalism, with minimum perspective of the State performance. In this context, health production modes have been influenced, reflected in the work process in this sector, with an intensification of work schedule as well as a deterioration of working conditions. Objectives: To identify and to characterize the scientific publications related to the precarization of the nursing labor in Brazil, and to assess the effects of labor precarization to nursing workers health. Methods: An integrative review was conducted between 2012 December and 2013 January using the Virtual Health Library, which includes, among others databases, LILACS, BDENF and SCIELO. Results: The precarization of nursing labor is related to the loss of worker rights, low salaries, multiple employment relationships, various forms of employment and long working hours, and precarious environments and working conditions. Conclusions: Nursing labor precarization is present in different nursing work environments, representing direct impact on the nursing workers health, causing physical and mental disabilities.
\end{abstract}

Keywords: Occupational health; Occupational health nursing; Working conditions; Labor relations.

1. Enfermeira. Doutoranda em Enfermagem - (PPGEnf/UERJ). Especialista em Enfermagem do Trabalho. Professora Assistente do Departamento de Enfermagem MédicoCirúrgica da Universidade do Estado do Rio de Janeiro. Rio de Janeiro, RJ, Brasil. E-mail: helenafg1@yahoo.com.br

2. Enfermeiro. Mestre em Enfermagem. Especialista em Enfermagem do Trabalho e Docência do Ensino Técnico. Enfermeiro do Rio de Janeiro, RJ, Brasil. E-mail: gleydy_fran@ hotmail.com

3. Enfermeira. Doutoranda em Enfermagem - (PPGEnf/UERJ). Especialista em Enfermagem do Trabalho e Estomaterapia. Professora Assistente do Departamento de Enfermagem Médico-Cirúrgica da Universidade do Estado do Rio de Janeiro. Rio de Janeiro, RJ, Brasil. E-mail: arianepires@oi.com.br.

4. Enfermeiro. Doutorando em Saúde Coletiva - (IMS/UERJ). Professor Assistente do Departamento de Enfermagem Médico-Cirúrgica da Universidade do Estado do Rio de Janeiro. Rio de Janeiro, RJ, Brasil. E-mail: rafaeljomar@yahoo.com.br.

5. Enfermeira. Doutora em Saúde Comunitária - (IMS/UERJ). Professora Associada do Departamento de Enfermagem Médico-Cirúrgica da Universidade do Estado do Rio de Janeiro. Rio de Janeiro, RJ, Brasil. E-mail: ellenperes@globo.com.

6. Enfermeira. Doutora em Enfermagem (UNICAMP). Especialista em Enfermagem do Trabalho. Professora Adjunta do Departamento de Enfermagem Médico-Cirúrgica da Universidade do Estado do Rio de Janeiro. Rio de Janeiro, RJ, Brasil. E-mail: cristiane.gallasch@gmail.co 


\section{INTRODUÇÃO}

0 trabalho é o eixo em torno do qual se organiza a vida, pois é por meio da inserção do homem no trabalho que ele se reproduz socialmente - reprodução social entendida como produção e consumo ${ }^{1}$. 0 setor saúde pode ser entendido como trabalho, pois faz parte do setor de serviços, além de possuir caráter social, já que o ser humano em sociedade é seu objeto de intervenção ${ }^{2}$. 0 trabalho em saúde é um trabalho imaterial essencial à vida humana, que se completa no ato da sua realização. Portanto, não produz bem material e seu produto é a própria realização da atividade, isto é, indissociável do processo que o produz. 0 trabalho em saúde, na atualidade, vem atendendo à lógica do mercado capitalista, na perspectiva de atuação mínima do Estado. Isto interfere diretamente nos modos de produção em saúde, refletindo no processo de trabalho neste setor, no qual se observa uma intensificação da terceirização dos serviços, bem como uma precarização das condições de trabalho ${ }^{3}$.

A constatação deste quadro de precarização das condições de trabalho por docentes de Enfermagem da UERJ, no âmbito do acompanhamento destes junto aos estudantes na realização de suas práticas acadêmicas nos cenários de ensino dos hospitais públicos, do tipo escola e geral, no município do Rio de Janeiro, levou os referidos docentes a desenvolverem o presente estudo.

É importante destacar que as principais características do novo padrão de acumulação do capital tem sido a intensificação da exploração da força de trabalho por meio do uso de novas tecnologias ou pela nova forma de organização da produção e do trabalho. Assim como nas relações de trabalho, que implica contratos precários, subcontratação, aumento da jornada de trabalho, entre outras formas de exploração no trabalho. Estes constituem uma complexa questão social, que agudiza a exclusão social4-6.

Neste contexto, os trabalhadores de enfermagem correspondem a uma força de trabalho de mais de um milhão de pessoas, e que tem por características da sua prática a inserção de seus agentes em todos os momentos do processo de trabalho em saúde ${ }^{7}$. No cenário laboral da saúde, encontram-se profissionais de enfermagem das diferentes categorias, isto é, enfermeiros, técnicos e auxiliares de enfermagem, cada qual com atribuições específicas e graus de instrução diferenciados. Estes profissionais são influenciados pelas mudanças que ocorrem na sociedade, em específico, as que se sucedem no mundo do trabalho. Dentre elas, a implementação de tecnologias, a precarização dos recursos humanos e materiais, além das transformações na forma como se executa o cuidado, que modificam o processo de trabalho da enfermagem, aumentando a pressão sobre o trabalhador em relação a seu desempenho e sua capacitação.

Assim, os trabalhadores de enfermagem, inseridos em um contexto neoliberal, vêm sofrendo inúmeros reveses com a precarização do trabalho, dentre os quais se citam: contratos trabalhistas precários, terceirização dos serviços, perda de direitos trabalhistas, desemprego, condições de trabalho precárias, sucateamento da máquina pública, escassez de recursos humanos e materiais, que permeiam o contexto hospitalar no qual os trabalhadores de enfermagem atuam. Cabe destacar que a precarização do trabalho interfere diretamente na saúde dos trabalhadores de enfermagem. Neste sentido,as condições de precariedade hoje existentes nos hospitais da rede pública podem levar enfermeiros ao desenvolvimento do sofrimento diante da necessidade de improvisação de materiais e equipamentos, e também da tentativa de prestar um cuidado mais humanizado ${ }^{9-10}$.

Entretanto, a insegurança gerada pelo receio do desemprego faz com que os trabalhadores se submetam a regimes e contratos de trabalho precários ${ }^{11}$. Algumas pesquisas sinalizam que a precarização do trabalho, embora seja uma construção histórica, pode, sim, ser modificável, pois adoecimentos e acidentes de trabalho podem ser evitados. A legislação precisa ser preservada e cumprida, e os direitos sociais não podem ser negociáveis, uma vez que é necessário resgatar a dignidade do trabalho e reduzir as barreiras entre os sujeitos coletivos em defesa dos direitos sociais ${ }^{12-13}$. Salienta-se ainda que a atual conjuntura social a que estão submetidos os trabalhadores de saúde, em especial, os trabalhadores de enfermagem, os quais correspondem a uma força de trabalho de $56 \%$, merece ser analisada e discutida, haja vista que existe, na atualidade, uma Política Nacional de Desprecarização do Trabalho que precisa ser cumprida ${ }^{14}$.

Diante disso, os objetivos do presente estudo são identificar e caracterizar a produção científica de enfermagem relacionada à precarização do trabalho de enfermagem no Brasil, e avaliar as repercussões da precarização do trabalho na saúde dos trabalhadores de enfermagem.

\section{REFERENCIAL TEÓRICO}

O termo precarização do trabalho tem sido utilizado para determinar perdas de direitos trabalhistas decorrentes das transformações processadas no mundo do trabalho e das políticas liberais próprias do intervencionismo mínimo do Estado. Estas mudanças oriundas do processo de reestruturação do capital surgem nos países capitalistas no pós-guerra ${ }^{15}$. Assim, o neoliberalismo se apresenta como um processo de reorganização do capital (econômico e político) que tem por mecanismos a privatização do Estado, a desregulamentação dos direitos do trabalho, a desmontagem do setor produtivo estatal e a reestruturação da produção e do trabalho ${ }^{16-17}$.

Ressalta-se que esta nova ordem tem levado a força humana que trabalha a uma destruição e/ou precarização, sem paralelos, em toda era moderna, e à degradação crescente do meio ambiente, pois, a relação 
metabólica entre homem, tecnologia e natureza, voltada para a produção de mercadorias (valor de troca), tem por premissas a valorização do capital, a destruição da natureza, o desemprego estrutural e a precarização do trabalho, levando a um processo de "desantropomorfização do trabalho"17-18. Em termos, a precarização do trabalho refere-se a um conjunto de mudanças em relação ao mercado de trabalho, condições de trabalho, qualificação dos trabalhadores e direitos trabalhistas, no contexto do processo de ruptura do modelo de desenvolvimento fordista e de emergência de um novo padrão produtivo ${ }^{19}$.

A flexibilização do processo produtivo e estruturação do sistema de produção (cadeia produtiva) envolve trabalhadores submetidos às diversas formas de contratação, recebendo salários diferenciados, mesmo para a realização de trabalhos semelhantes. 0 processo de produção passa a ser desenvolvido de diferentes formas, tais como: prestação de serviços, part-time, empresas terceiras, cooperativas, trabalho por tempo determinado, trabalhos flexíveis, e a mais diversa variedade de precarização que assola o trabalhador de enfermagem ${ }^{18}$. Deste modo, por implicar perdas de direitos trabalhistas, este processo tem sido chamado de precarização e tem interferido diretamente nos sindicatos e nas mobilizações sociais por melhores condições de trabalho ${ }^{15}$.

Estas mudanças relativas ao trabalho não têm sido exclusivas dos setores de produção industrial, pois o que se observa é uma ampliação para todos os setores produtivos, dentre eles o setor de serviços ${ }^{15}$. Destaca-se, então, o setor saúde, onde vem elevando-se o quantitativo de trabalhadores sem as garantias trabalhistas de que gozam os demais trabalhadores assalariados, podendo-se observar: contratos temporários; trabalhadores contratados para realizar atividades especiais (regime de plantão) flexibilização na contratação de agentes comunitários de saúde e das equipes de saúde da família, e o trabalho temporário previsto no Programa de Interiorização do Trabalho em Saúde ${ }^{15}$.

Neste contexto, destaca-se uma pesquisa realizada no cenário hospitalar, onde se constatou perdas de direitos trabalhistas como: férias, décimo terceiro salário, aumento de sobrecarga de trabalho, déficit de recursos humanos e materiais, tanto de forma qualitativa como também quantitativamente, assim, como ausência de concursos públicos para contratação de funcionários estatutários, aumento de contratação temporária, ou seja, o subemprego ${ }^{20}$. Segundo os autores desse estudo a dificuldade de relacionamento interpessoal dentro da equipe de enfermagem, aumento do uso da tecnologia que afasta o profissional do processo de cuidar do ser humano, aumento das adaptações e improvisações dificultam o andamento do trabalho da enfermagem.

Há que se destacar que a terceirização tem sido utilizada tanto pelo setor público quanto pelo privado, a fim de diminuir os gastos com a força de trabalho, escapar das conquistas salariais e dos direitos trabalhistas. Entretanto, torna-se imperioso considerar que flexibilização nas formas de contrato não é sinônimo de "precarização", apesar de, no Brasil, essas iniciativas estarem sendo utilizadas para a redução de custos com a força de trabalho e para a precarização ${ }^{1,21}$. Assim, a precarização tem sentido de perda ou ausência de direitos trabalhistas. 0 trabalho precário está relacionado aos vínculos de trabalho no Sistema Único de Saúde que não garantem os direitos trabalhistas e previdenciários consagrados em lei ${ }^{15}$.

Os sindicatos afirmam que o trabalho precário está caracterizado não apenas como ausência de direitos trabalhistas e previdenciários consagrados em lei, mas também pela ausência de concurso público ou processo seletivo público para cargo permanente ou emprego público no Sistema Único de Saúde ${ }^{15}$.

\section{MÉTODO}

Trata-se de uma revisão integrativa da literatura ${ }^{22}$ que permite a busca, a avaliação crítica e a síntese das evidências disponíveis acerca da temática, sendo o seu produto final uma fotografia do estado atual do conhecimento sobre o tema investigado, a implementação de intervenções efetivas na assistência à saúde, a redução de custos, bem como a identificação de lacunas que direcionam para o desenvolvimento de futuras pesquisas ${ }^{23}$. Para a elaboração dessa revisão integrativa e para que se possa contribuir para a construção de análises de pesquisa e construção de novos saberes, faz-se necessário percorrer seis etapas distintas $22-23$.

Neste sentido, partiu-se do questionamento acerca de quais seriam as perspectivas da produção científica sobre a precarização do trabalho de enfermagem e quais seriam as repercussões deste processo na saúde dos trabalhadores de enfermagem. A primeira fase refere-se ao estabelecimento da questão norteadora que envolveu toda a pesquisa, a escolha e a definição do tema, e a identificação de palavraschave ou descritores. Foram selecionadas as seguintes palavras-chave correlacionadas: "Precarização do Trabalho e Saúde"; "Precarização do Trabalho e Enfermagem" e "Precarização do Trabalho e Saúde do Trabalhador”.

$\mathrm{Na}$ segunda, os critérios de inclusão e de exclusão a serem estabelecidos. Em relação ao recorte temporal, foi delimitado o período compreendido entre 2002 a 2012, considerando-se que o tema precarização do trabalho de enfermagem e as repercussões na saúde destes trabalhadores consistem em um problema relevante que merece ser investigado cientificamente e têm condições de ser formulado e delimitado. Entre as publicações encontradas, foram selecionados somente produções na íntegra, artigos publicados em periódicos brasileiros e em português que tratavam do tema investigado. Foram excluídos os artigos encontrados em mais de uma Base de Dados. Estes foram contabilizados e analisados como apenas um a fim de evitar repetições. Também foram excluídos os artigos de acesso indisponível ou 
inconsistentes com o objeto de estudo proposto.

A busca foi realizada na Biblioteca Virtual em Saúde (BVS), a qual inclui, dentre outras, as seguintes bases de dados: Literatura Latino-Americana e do Caribe em Ciências da Saúde (LILACS), Scientific Eletronic Library Online (SCIELO), e Base de Dados da Enfermagem (BDENF). A coleta de dados do presente estudo foi realizada entre os meses de dezembro de 2012 e janeiro de 2013.

A terceira etapa da revisão integrativa de literatura define as informações que devem ser extraídas. Devese, portanto, organizar e sumarizar as informações encontradas. A organização, a categorização e a análise dos dados ocorreram através do preenchimento de um instrumento do tipo questionário confeccionado pelos autores para sistematizar a coleta dos dados. 0 instrumento foi previamente testado a fim de adequá-lo ao propósito da pesquisa. Neste instrumento, foram adotadas as seguintes variáveis que contemplam itens a seguir: dados referentes à identificação do manuscrito: autor, título, ano de publicação, local do estudo, objeto de estudo, objetivos, características metodológicas do estudo, técnica de coleta de dados, sujeitos ou população do estudo, tratamento dos dados e síntese da publicação.

A quarta e a quinta etapas foram desenvolvidas ao longo do corpo textual. Para fins de conceituação, a quarta etapa corresponde à fase de análise, avaliação, inclusão e exclusão dos estudos através de uma análise crítica daqueles selecionados. Já durante a quinta etapa, ocorreu a interpretação e a discussão dos resultados encontrados, nos quais se revelam as lacunas de conhecimento e as sugestões pertinentes para melhoria da qualidade da ação profissional.

A sexta e última etapa é determinada pela apresentação da revisão. A criação de um documento que descreva detalhadamente a revisão integrativa. Esta etapa consiste na elaboração do documento que deve contemplar a descrição das etapas percorridas pelo revisor e os principais resultados evidenciados na análise dos artigos incluídos. É um trabalho de extrema importância, já que produz impacto devido ao acúmulo do conhecimento existente sobre a temática pesquisada ${ }^{21}$, ou seja, após a aquisição do material bibliográfico, realizou-se a leitura na íntegra dos textos a fim de identificar as informações relevantes e os dados imprescindíveis para estabelecer relações entre essas informações/dados e o problema proposto no referido estudo, para, em seguida, analisar a consistência das informações e dos dados apresentados pelos autores. Após a seleção, fez-se um mapeamento das produções e destacaram-se as principais categorias.

Infere-se que, ao final da análise, a bibliografia potencial constituiu-se de sete trabalhos científicos na íntegra, em português, e os dados levantados foram analisados por meio da análise de conteúdo temático. Os resultados são apresentados de forma descritiva, fazendo uso de tabelas, objetivando-se captar evidências da precarização do trabalho no contexto hospitalar e suas principais repercussões na saúde dos trabalhadores da área de enfermagem.

\section{RESULTADOS E DISCUSSÃO}

Mediante os achados emergiram duas categorias intituladas: perfil da produção científica sobre a precarização do trabalho de enfermagem, e as diferentes faces da precarização do trabalho de enfermagem e suas repercussões na saúde do trabalhador.

\section{0 perfil da produção científica sobre a precarização do trabalho de enfermagem}

De acordo com a busca através das palavras-chave,foram encontradas 194 produções bibliográficas, das quais 114 eram textos completos. Entre as produções encontradas, foram selecionadas aquelas pertencentes ao campo de pesquisa localizado no Brasil e cujo objeto de estudo ou temática está relacionada ao questionamento incluído neste trabalho. Desta forma, apenas sete publicações foram selecionadas, resultantes dos critérios de inclusão pré-estabelecidos anteriormente. As demais publicações foram excluídas por indisponibilidade de acesso gratuito ou por incongruência com o objeto deste estudo.

Das produções encontradas, duas caracterizam-se como dissertações de mestrado em enfermagem oriundas do programa de pós-graduação em enfermagem da Universidade do Estado do Rio de Janeiro; uma tese de doutorado em enfermagem do Programa de Pós-Graduação em Enfermagem, da Universidade de Santa Catarina; três artigos científicos, sendo um publicado na Revista de Enfermagem UERJ, um na Revista de Enfermagem Anna Nery e um na Physis Revista de Saúde Coletiva do Instituto de Medicina Social da UERJ. Mediante os trabalhos levantados, buscou-se evidenciar a distribuição dos estudos em relação às variáveis: título, autores, ano de publicação, e objetivos.

No Quadro 1, são apresentadas as publicações selecionadas para este estudo. podem ser vistas segundo o título das mesmas, os autores, o ano de publicação, e os objetivos da pesquisa, a abordagem metodológica, os sujeitos/população do estudo.

Em relação à abordagem metodológica e aos sujeitos/ população das pesquisas, observa-se a predominância de abordagens qualitativas, do tipo descritiva, tendo por sujeitos trabalhadores de enfermagem, conforme demonstrado no Quadro 2.

Ressalta-se que os estudos utilizaram diferentes técnicas de coletas de dados, tais como: entrevista semiestruturada, entrevistas fechadas, questionários, observação assistemática, observação sistemática, grupos. Pode-se inferir que as abordagens utilizadas propiciaram uma riqueza de resultados, haja vista que os cenários foram diversos, bem como as diferentes formas de coleta de dados. 
Quadro 1: Distribuição dos estudos, segundo título, autores/ano de publicação e objetivos. Rio de Janeiro, RJ, 2015.

\begin{tabular}{|c|c|c|}
\hline Título & $\begin{array}{c}\text { Autores/Ano } \\
\text { publicação }\end{array}$ & Objetivos \\
\hline $\begin{array}{l}\text { Interfaces dos aspectos } \\
\text { estruturais, organizacionais e } \\
\text { relacionais do trabalho de } \\
\text { enfermagem e o desgaste do } \\
\text { trabalhador }\end{array}$ & $\begin{array}{l}\text { Gelbcke } \\
(2002)\end{array}$ & $\begin{array}{l}\text { Determinar o que, na organização do trabalho } \\
\text { da enfermagem, em seus aspectos estruturais, } \\
\text { organizacionais e relacionais, tem sido } \\
\text { determinante do processo de desgaste dos } \\
\text { trabalhadores de enfermagem, segundo sua } \\
\text { própria percepção; Refletir sobre estratégias de } \\
\text { re-organização do trabalho da enfermagem, no } \\
\text { sentido de minimizar o desgaste físico e } \\
\text { psíquico dos trabalhadores. }\end{array}$ \\
\hline $\begin{array}{l}\text { Formas de produzir saúde no } \\
\text { trabalho hospitalar: uma } \\
\text { intervenção em psicologia }\end{array}$ & $\begin{array}{l}\text { Araújo et al } \\
(2002)\end{array}$ & $\begin{array}{l}\text { Conhecer a realidade de trabalho e as } \\
\text { repercussões para a saúde dos profissionais que } \\
\text { desenvolviam suas atividades no setor de } \\
\text { pediatria, visando, em última instância, produzir } \\
\text { um espaço de reflexão e crítica que pudesse } \\
\text { funcionar como dispositivo de mudança, tanto } \\
\text { das condições de trabalho tidas como } \\
\text { causadores de sofrimento, como das relações } \\
\text { entre os participantes da equipe de enfermagem. }\end{array}$ \\
\hline $\begin{array}{l}\text { As influências do ambiente de } \\
\text { trabalho na saúde dos } \\
\text { trabalhadores de enfermagem }\end{array}$ & $\begin{array}{l}\text { Molento } \\
(2005)\end{array}$ & $\begin{array}{l}\text { Identificar os fatores ambientais do trabalho que } \\
\text { influenciam a saúde desses trabalhadores. } \\
\text { Analisar os fatores ambientais do trabalho que } \\
\text { repercutem na saúde desses trabalhadores. }\end{array}$ \\
\hline A visibilidade dos escondidos & $\begin{array}{l}\text { Costa } \quad \mathrm{e} \\
\text { Tambellini } \\
(2009)\end{array}$ & $\begin{array}{l}\text { Descrever as dimensões humanas implicadas } \\
\text { nesse processo de trabalho,traduzindo o nível de } \\
\text { exploração de suas relações precárias. }\end{array}$ \\
\hline $\begin{array}{l}\text { O trabalho da enfermagem e a } \\
\text { criatividade: adaptações e } \\
\text { improvisações hospitalares }\end{array}$ & $\begin{array}{lll}\text { Souza } & \text { et } & \text { al } \\
(2009) & & \end{array}$ & $\begin{array}{l}\text { Identificar no ambiente hospitalar as adaptações } \\
\text { e improvisações de materiais e equipamentos } \\
\text { realizadas pelos trabalhadores de enfermagem; } \\
\text { e discutir a importância das adaptações e } \\
\text { improvisações para o trabalho de enfermagem. }\end{array}$ \\
\hline $\begin{array}{l}\text { Repercussões psicofísicas } \\
\text { saúde dos enfermeiros } \\
\text { adaptação e improvisação de } \\
\text { materiais hospitalares }\end{array}$ & $\begin{array}{lll}\text { Souza } & \text { et } & \text { al } \\
(2010) & & \end{array}$ & $\begin{array}{l}\text { Analisar os sentimentos dos enfermeiros diante } \\
\text { da necessidade de adaptação e de improvisação } \\
\text { de materiais e de equipamentos no ambiente } \\
\text { hospitalar e discutir as repercussões na saúde do } \\
\text { enfermeiro diante da necessidade de } \\
\text { improvisação e adaptação de materiais e de } \\
\text { equipamentos. }\end{array}$ \\
\hline $\begin{array}{l}\text { As adaptações e improvisações } \\
\text { no trabalho hospitalar e suas } \\
\text { implicações na saúde do } \\
\text { trabalhador de enfermagem }\end{array}$ & $\begin{array}{l}\text { Cunha, L. S. } \\
(2010)\end{array}$ & $\begin{array}{l}\text { Identificar a percepção dos trabalhadores de } \\
\text { enfermagem sobre as adaptações e } \\
\text { improvisações; descrever as situações que } \\
\text { conduzem os trabalhadores de enfermagem à } \\
\text { realização desta prática e analisar as } \\
\text { implicações das adaptações e improvisações na } \\
\text { saúde dos trabalhadores de enfermagem. }\end{array}$ \\
\hline
\end{tabular}


Quadro 2: Distribuição dos estudos quanto à abordagem metodológica e população da pesquisa. Rio de Janeiro, RJ, 2015.

\begin{tabular}{|l|l|}
\hline \multicolumn{1}{|c|}{ Abordagem metodológica } & \multicolumn{1}{c|}{ Sujeitos/População da pesquisa } \\
\hline $\begin{array}{l}\text { Qualitativa- utilizando o materialismo } \\
\text { histórico dialético }\end{array}$ & Trabalhadores de enfermagem \\
\hline Método dos encontros coletivos & Equipe de enfermagem \\
\hline Qualitativa- descritiva e exploratória & Trabalhadores de enfermagem \\
\hline Quali-quantitativa- descritiva & Trabalhadores de enfermagem \\
\hline Qualitativa- descritiva & Enfermeiros \\
\hline Qualitativa- descritiva e exploratória & Equipe de enfermagem \\
\hline
\end{tabular}

\section{As diferentes faces da precarização do trabalho de enfermagem e suas repercussões na saúde do trabalhador}

No Brasil,a precarização do trabalho decorre de um lento processo de desmonte do Setor Público, a partir da política neoliberal iniciada na década de 90 . Nesta perspectiva, - Estado brasileiro passou, então, a assumir uma feição mais liberal, no que concerne a desregulamentação do trabalho e do bem-estar, internalizando este processo nas relações de trabalho em diferentes áreas, dentre elas, a saúde. Pode-se inferir que os achados de estudos datados a partir de 2002 sobre trabalhadores de enfermagem estejam correlacionados à intensificação deste processo de precarização no setor saúde, no início do século XXI, e pelas diferentes repercussões desta precarização no mercado de trabalho. Daí o interesse por tal temática.

A inserção dos trabalhadores de saúde no mercado de trabalho indica forte urbanização, especialização, múltiplos vínculos, baixa remuneração, aumento da força de trabalho feminina, aumento da jornada de trabalho e informalidade nas relações de trabalho, perda/ausência dos direitos trabalhistas conquistados ao longo das décadas, tais como férias remuneradas, décimo terceiro salário, Programa de Integração Social (PIS), licenças médicas, salário família. Tendência similar à economia contemporânea, ao utilizar da flexibilização para a contratação da força de trabalho ${ }^{18,24}$.

Embora os estudos tenham diferentes objetivos, todos buscam elucidar as relações de trabalho da enfermagem e a repercussão destas relações na saúde destes profissionais. Estudo anterior demonstra que a precarização no ambiente de trabalho de enfermagem está ligada à falta de vínculo empregatício e à falta de treinamento profissional adequado. Ainda, discorre sobre a existência de elementos de penosidades no trabalho, como carga física, psíquica e mental, e os riscos aos quais estão expostos estes profissionais ${ }^{25}$.

Nesta perspectiva, destacam-se os fatores ambientais relacionados com as condições de trabalho, no que se refere a formas contratuais, assim como as condições objetivas de trabalho, cargas de trabalho e riscos ocupacionais, que podem isoladas ou conjuntamente, influenciar negativamente a saúde dos trabalhadores de enfermagem ${ }^{25}$. A organização do trabalho de enfermagem em seus aspectos estruturais, organizacionais e relacionais, tem sido determinante no processo de desgaste dos trabalhadores de enfermagem. Ressalta-se, ainda, que os aspectos estruturais, como sobrecarga de trabalho em decorrência do duplo vínculo e baixos salários, determinados pela conjuntura político-econômica, vêm repercutindo no sucateamento do setor saúde e na saúde dos trabalhadores, assim como, na qualidade da assistência prestada ${ }^{26}$

Entretanto, o modelo assistencial ainda incipiente, transitando entre o integral e o funcional, a funcionalidade da assistência, a rotatividade de setores, dificuldades para trocas de plantão, divisão do trabalho parcelar, a alocação da força de trabalho, somadas às condições de trabalho precárias (em relação a pessoal, material e infraestrutura), e as gerências autocráticas geram no trabalhador de enfermagem um desgaste físico e psíquico ${ }^{26}$.

Observou-se também, em estudo desenvolvido num hospital, que as condições e a organização do trabalho têm favorecido o adoecimento dos trabalhadores de enfermagem, devido a um processo de desqualificação e de precarização do serviço público ${ }^{27}$. Ao descrever a precariedade do funcionamento de um hospital, o autor coloca que outro obstáculo para a qualidade do trabalho, que gera grande tensão nos trabalhadores, diz respeito à falta de material, chegando a declarar que "faltam leitos, equipamentos, medicamentos e materiais, além da insuficiência no número de profissionais"27.

Mediante a precarização das condições de trabalho, quadro que conduz a uma insuficiência e/ou inadequação dos insumos hospitalares, os enfermeiros podem vivenciar sentimentos de sofrimento e de desgaste emocional, decorrentes do gasto de tempo, e do esforço físico e mental dispendido para adaptar e improvisar materiais, e acabam por gerar na saúde destes trabalhadores sofrimento psíquico, desgaste físico e adoecimento 9,28 .

As repercussões advindas da necessidade de adaptar/ improvisar são as mais variadas, destacando-se aumento do ritmo de trabalho, aumento do esforço físico, necessidade de peregrinação em outros setores para a busca de 
materiais, aliado ao esforço físico que já é inerente ao trabalho de enfermagem, principalmente quando cuidam de clientes acamados. Neste sentido, os trabalhadores, sentem-se desgastados, com sentimentos de raiva, angústia, ansiedade, desmotivação e estresse ${ }^{29}$.

Atualmente, em face à precariedade das relações de trabalho, as doenças assumem formas mais subjetivas, tornando difícil sua associação com a atividade laboral. Aponta-se, ainda, que não é possível afirmar que insônia, medo, obesidade, entre outros, são sintomas de trabalhadores precarizados, mas pode-se inferir que "novas" doenças ocupacionais acometem os trabalhadores, tendo por causas o trabalho precário ${ }^{30}$. Outra questão aludida refere-se ao processo de precarização do setor público, em especial o da saúde, ao ressaltar que, no ambiente hospitalar, o trabalhador é explorado ao exercer suas funções, em condições insalubres, com baixos salários e extensas jornadas de trabalho, o que, por sua vez, vem enfraquecendo os sindicatos e as lutas sociais, inviabilizando o trabalho digno, e os direitos sociais conquistados. Esta nova política tem desqualificado o setor público e fortalecido a precarização do trabalho ${ }^{27}$.

Assim, os trabalhadores de enfermagem atuam em ambientes insalubres e penosos, que não oferecem condições adequadas à saúde, reforçado pela precarização do trabalho, quer seja pelo excesso de trabalho, acúmulo de horas trabalhadas, falta de material, má remuneração, e instabilidade pelo vínculo empregatício. Todas estas situações irão propiciar adoecimento físico e mental, interferindo na qualidade de vida do trabalhador e na assistência prestada ${ }^{9,28}$.

Ressalta-se que a falta de proteção social, a insegurança e o desrespeito às limitações físicas do corpo do trabalhador são consequências do processo de flexibilização da contratação da força de trabalho. 0 medo do desemprego e as doenças que sobre ele advêm, constituem reações desta conjuntura ${ }^{30}$.Vale frisar que a situação da precarização e desmonte do setor público vêm se concretizando por meio das reformas econômicas, políticas e jurídicas, e por discursos que contribuem para a "construção de subjetividades individualizadas, homogeneizadas e apáticas", atendendo a uma lógica de dominação incontestável ${ }^{27}$. Assim, a relação precária de trabalho dificulta a organização da classe trabalhadora, legitimando o poder do capital sobre o trabalho. Ao fragmentar e combater o sindicalismo classista, desmonte dos direitos sociais, e estímulo ao sindicalismo de resultado. "Por isso, a precarização do trabalho constitui-se num problema de Estado, e não somente de reorganização econômica da produção" 30

Deste modo, a precarização do trabalho assume diferentes faces, desde a desregulamentação dos direitos trabalhistas, a precarização dos ambientes de trabalho e das condições de trabalho, que irão repercutir diretamente na saúde dos trabalhadores de enfermagem, causando problemas de ordem física, psíquica e social.

\section{CONCLUSÕES}

Ao analisar a produção científica sobre a precarização do trabalho de enfermagem, destaca-se a predominância de estudos qualitativos, utilizando diferentes técnicas de coletas de dados. Na ordem cronológica, os primeiros estudos levantados datam do ano de 2002. Embora tenham diferentes objetivos, pode-se acentuar que todos buscam elucidar as relações de trabalho dos enfermeiros e as repercussões destas relações na saúde destes profissionais.

As publicações identificadas sobre precarização do trabalho de enfermagem relacionavam-se à perda de direitos trabalhistas e suas repercussões como a baixa remuneração, os múltiplos vínculos, as diversas formas de contratação e jornadas de trabalho extensas, entre outros, bem como a precarização dos ambientes de trabalho e das condições de trabalho, às quais são submetidos os trabalhadores de enfermagem. Evidenciou-se, de modo geral, uma carência de estudos sobre precarização na área do trabalho de enfermagem e suas repercussões para a saúde do trabalhador. Nesta perspectiva, sugere-se o desenvolvimento de novos estudos, não somente porque essa situação ocorre na área, mas também porque se constitui uma necessidade, principalmente, pela mudança de paradigma no modelo de produção.

As repercussões da precarização do trabalho interferem diretamente na saúde dos trabalhadores de enfermagem, resultando principalmente estresse, sobrecarga, ansiedade, lombalgias, portanto, adoecimento físico e psíquico. Diante do exposto, torna-se imprescindível promover maior abordagem sobre a referida temática junto aos trabalhadores de enfermagem, a fim de que se possam criar mecanismos e estratégias coletivas de fortalecimento dos diferentes agentes sociais, na luta por um trabalho digno e saudável que favoreça a expressão da subjetividade e criatividade do trabalhador, tornando-se, assim, numa atividade que assegure a saúde, o bem-estar e reconhecimento, fonte de geração de prazer e satisfação.

\section{REFERÊNCIAS}

1. Facchini LA. Por que a doença? A inferência causal e os marcos teóricos da análise. In: Buschinelli JTP, Rocha LE, Rigotto RM. Isto é trabalho de gente? Vida, doença e trabalho no Brasil. Petrópolis: Vozes; 1994.

2. Garcia MAA, Pinto ATBCZ, Odoni APC, Longhi BS, Machado LI, Lonek MDS et al. Interdisciplinaridade e integralidade no ensino em saúde. Rev Cienc Med. 2006; 15(6): 473-485.

3. Pires D. A estrutura objetiva do trabalho em saúde. In: Leopardi MT. Processo de trabalho em saúde: organização e subjetividade. Florianópolis: Programa de Pós Graduação em Enfermagem UFSC. São José: Ed. Papa-Livros, 1999.

4. Navarro VL. $\mathrm{O}$ trabalho e a saúde do trabalhador na indústria de calçados. São Paulo Perspec. 2003; 17(15): 32-34.

5. Conserva MS, Araújo AJS. Informalidade e precarização nos mundos do trabalho. Teor Pol e Soc. 2008; 1(1): 75-91. 
6. Druck G. Trabalho, precarizaçao e resistência: novos e velhos desafios? Cad CRH. 2011; 24(1): 37-57.

7. Araújo MJS. A consulta de enfermagem no contexto da prática de enfermagem. Brasíli: Série documento: ABEn; 1991.

8. Murofuse NT. $O$ adoecimento dos trabalhadores de enfermagem da fundação hospitalar do Estado de Minas Gerais: Reflexo das mudanças no mundo do trabalho. Ribeirão Preto. Tese [Doutorado em Enfermagem] - Universidade de São Paulo; 2004.

9. Souza NVDO, Santos DM, Anunciação CT, Thiengo PCS. O trabalho da enfermagem e a criatividade: adaptações e improvisações hospitalares. Rev Enferm UERJ. 2009; 17(3): 356-361.

10. Gonçalves FGA, Souza NVDO, Zeitoune RCG, Adame GFPL, Nascimento SMP. Impactos do neoliberalismo no trabalho hospitalar de enfermagem. Texto Contexto Enferm. 2015; 24( 3 ): 646-53.

11. Elias MA, Navarro VL. A relação entre o trabalho, a saúde e as condições de vida: negatividade e positividade no trabalho das profissionais de enfermagem de um hospital escola. Rev LatAmer Enferm. 2006; 14(4): 517-525.

12. Kremer A, Faria JH. Reestruturação produtiva e precarização do trabalho: o mundo do trabalho em transformação. Rev Admin. 2005; 40(3): 266-279.

13. Franco T, Druck G, Seligmann-Silva E. As novas relações de trabalho, o desgaste mental do trabalhador e os transtornos mentais no trabalho precarizado. RBSO. 2010; 35(122): 229-248.

14. Brasil. Ministério da Saúde. Secretaria da Gestão do Trabalho e da Educação na Saúde. Departamento de Gestão e da Regulação do Trabalho em Saúde. Programa nacional de desprecarização do trabalho no SUS. Brasília: Editora do Ministério da Saúde; 2006.

15. Pires D. Reestruturação Produtiva e Trabalho em Saúde no Brasil. São Paulo: Anna Blume; 2008.

16. Antunes R. Os sentidos do trabalho: ensaio sobre a afirmação e a negação do trabalho. São Paulo: Bomtempo; 2009.

17. Mészáros, I. Beyond capital: Towards a theory of transition. Londres: Merlin Press, 1995.

18. Antunes R.Adeus ao Trabalho? ensaios sobre as metamorfoses e a centralidade do mundo do trabalho. $15^{a}$ edição. São Paulo: Cortez; 2011.

19. Mattoso JEL. A Desordem do Trabalho. São Paulo: Página Aberta/Escrita; 1995.

20. Gonçalves FGA, Leite GFP. O modelo neoliberal e suas repercussões para o trabalho de enfermagem. Rio de Janeiro. Dissertação [Mestrado em Enfermagem] - Universidade do Estado do Rio de Janeiro; 2011.

21. Pires DE, Gelbcke FL, Matos E. Current labor changes and their implications for the health care workforce. In: 7th World Conference on Injury Prevention and Safety Promotion, (6-9 June, 2004) Vienna, (Austria). Anais Vienna, 2004. 612-613.

22. Souza MT, Silva MD, Carvalho R. Revisão integrativa: o que é e como fazer. Einstein. 2010; 8(1): 102-106.

23. Mendes KDS, Silveira RCCP, Galvão CM. Revisão integrativa: método de pesquisa para a incorporação de evidências na saúde e na enfermagem. Texto Contexto Enferm. 2008; 17(4): 758-64.
24. Nogueira R. Problemas da gestão de recursos humanos no Ministério da Saúde. Brasília: Observa RH/NESP/CEAM/UnB; 2006.

25. Molento FHB. As influências do ambiente de trabalho na saúde dos trabalhadores de enfermagem. Rio de Janeiro. Dissertação [Mestrado em Enfermagem] - Universidade do Estado do Rio de Janeiro; 2005.

26. Gelbcke FL.Interfaces dos aspectos estruturais,organizacionais e relacionais do trabalho de enfermagem e o desgaste do trabalhador. Florianópolis. Tese [Doutorado em Enfermagem] - Universidade Federal de Santa Catarina; 2002.

27. Araújo MD, Busnardo EA, Marchiori FM, Lima MF, Endlich TM. Formas de produzir saúde no trabalho hospitalar: uma intervenção em psicologia. Cad psicol soc trab. 2002; 5: 37-49.

28. Souza NVDO, Santos DM, Ramos EL, Anunciação CT, Thiengo PCS, Fernandez MC. Repercussões psicofísicas na saúde dos enfermeiros da adaptação e improvisação de matérias hospitalares. Escola Anna Nery. 2010; 14(2): 236-243.

29. Cunha LS.As Adaptações e improvisações no trabalho hospitalar e suas implicações na saúde do trabalhador de enfermagem. Rio de Janeiro. Dissertação [Mestrado em Enfermagem] Universidade do Estado do Rio de Janeiro; 2010.

30. Costa DO, Tambellini AT. A visibilidade dos escondidos. Physis. 2009; 19(4): 953-968. 